Pure \& Appl. Chem., Vol. 57, No. 9, pp. 1235-1244, 1985.

Printed in Great Britain.

(C) 1985 IUPAC

\title{
Dissociation of molecules in plasma and gas: the energy
}

\author{
A. V. Eletskii and B. M. Smirnov \\ Institute of Thermophysics, Novosibirsk, USSR.
}

\begin{abstract}
Various physical mechanisms of dissociation of molecules in plasma and gas are observed. Experimental data on energy cost of atoms for molecular dissociation at diverse conditions are analyzed. "aximal attainable values of this parameter for molecular dissociation in gas discharge, at electrnn beam irradiation of gas, in result of photodissociation of molecules, at a thermal heating.
\end{abstract}

\section{INTRODUCTION}

Many chemical processes in a gas or a plasma proceed with a participation of atoms or radicals. In order to accomplish this process one needs at the first stage to break the molecule into components. Since there are many secondary processes in the considered manner of energy insertion to a system, to form free atoms one needs to introduce into the system a higher energy than that necessary for a molecule dissociation. An energy characteristic describing efficiency of the considered way for energy introduction to the system for dissociation of molecules, is an energy cost of atom or radical $\mathcal{E}$. This value is the ratio of energy introduced into the system to the total amount of atoms formed. By comparing various ways of molecule dissociation consumptions of energy one can valuate an efficiency of a corresponding method of energy insertion. This analysis was performed in the present review ( see also $[1]$ ).

Among various ways of molecule dissociation in gas and plasma we shall consider an atom generation in a gas discharge, under the effect of an eleotron beam and ultraviolet radiation, as well as while heated a gas in an arc discharge or near a heated surface. These are the main ways of dissociation of molecules. We have some amount of the needed information for a limited number of molecules, such as fluorine, oxygen, nitrogen, carbon dioxide, which are concermed with certain applied problems.

Let us note that an energy cost of atom generation exceeds always an energy of breaking of a corresponding molecule bond, since along withe dissociation of molecules a wide variety of other processes proceeds in the systems; in particular, an excitation of vibrational and electron states of molecules. A major portion of energy inserted initially into a gas is consumed by these processes. As a result of relaxational processes this energy is transformed to a heat. Thereby the energy cost of atom formation characterizes also a degree of gas heating at a corresponding efficiency of the process. This circumstance is the most essential in the event when 
the process proceeds at a low temperature; it confines the process potentialities.

Information on an energy cost of atomic fluorine formation from a molecular one in a variety of ways is collected in Table 1. Considerable information on this subject is connected with the use of an atomic fluorine in chemical HF-lasers as well as to perform nonequlibrium chemical processes with formation of fluorine metastable compounds of the $\mathrm{KrF}_{2}$ type.

Table 1

Energy cost of fluorine atom formation

\begin{tabular}{|c|c|c|c|}
\hline Way of influence & $\begin{array}{l}\text { Energy } \\
\text { cost, eV }\end{array}$ & References & Notes \\
\hline \multirow[t]{4}{*}{ Gas discharge } & $6-8$ & [2] & $\begin{array}{l}\text { A glow discharge in a molecu- } \\
\text { lar fluorine }\end{array}$ \\
\hline & 60 & [3] & $\begin{array}{l}\text { UHF- discharge in a mixture: } \\
\mathrm{Ar}: \mathrm{F}_{2}(1 \mathrm{n}: 1), \text { fluorine dissoci- } \\
\text { ation } 90 \% .\end{array}$ \\
\hline & $3-40$ & [4] & $\begin{array}{l}\text { Glow discharge, fluorine pres- } \\
\text { sure } 0.25-5 \text { Torr, churrent den- } \\
\text { sity up to } 60 \mathrm{~mA} / \mathrm{cm}^{2} \text { tempera- } \\
\text { ture - from room to } 680 \mathrm{~K} \text {. }\end{array}$ \\
\hline & 3 & {$[5]$} & $\begin{array}{l}\text { UHF- discharge in fluorine, } \\
\text { pressure } 32 \text { Torr, input power } \\
0.1-2 \mathrm{kw} \text {, frequencv } 8 \mathrm{mHz} \text {. }\end{array}$ \\
\hline \multirow[t]{4}{*}{ Electron beam } & 4,5 & {$[6]$} & $\begin{array}{l}\text { Electron energy } 120 \mathrm{KeV} \text {, mixtu- } \\
\text { re } \mathrm{SF}_{6}: \mathrm{H}_{2}(11: 1)\end{array}$ \\
\hline & 6 & {$[7]$} & $\begin{array}{l}\text { Electron energy } 120 \mathrm{KeV} \text {, mixtu- } \\
\text { re He:Ar: } \mathrm{F}_{2}: \mathrm{H}_{2}(54: 34: 6: 6) \text {, cost } \\
\text { of a pair of charged particles } \\
24 \mathrm{eV} \text {. }\end{array}$ \\
\hline & 10 & [8] & $\begin{array}{l}\text { Electron energy } 40-50 \mathrm{KeV} \text {, mix- } \\
\text { ture He: } \mathrm{F} \text { : } \mathrm{HCl}: \mathrm{CO}_{2}(94: 4: 1: 1) \text {, } \\
3-4 \text { fluorIne atoms are formed } \\
\text { per every pair of charged par- } \\
\text { ticles }\end{array}$ \\
\hline & 5 & [9] & $\begin{array}{l}\text { Electron energy - } 1 \mathrm{MeV} \text { in mo- } \\
\text { lecular fluorine }\end{array}$ \\
\hline $\begin{array}{l}\text { Ultraviolet } \\
\text { radiation }\end{array}$ & $\begin{array}{l}1.1- \\
-2.5\end{array}$ & - & $\begin{array}{l}\text { Maximum cross-section } 28^{f} \text { photo- } \\
\text { dissociation } F_{2}\left(2 \cdot 10^{-2} \mathrm{~cm}\right) \\
\text { conforms with a wave - ength } \\
0.3 \mu \text { which an energy atom } \\
\text { cost } 2.1 \mathrm{eV} \text { corresponds to. }\end{array}$ \\
\hline Heated surface & $3-5$ & {$[10-12]$} & $\begin{array}{l}\text { Temperature of nickel surface } \\
\text { about } 900 \mathrm{~K} \text {, fluorine pressure } \\
10-50 \text { Torr. }\end{array}$ \\
\hline
\end{tabular}

Referring to Table 1, let us analyze various ways of molecule dissociation. In gas-discharge facilities an energy cost of atom can significantly depend on a sort of gas or type of discharge. This has to do with the fact that the process of molecule dissociation by an electron impact involves a molecule excitation to a repulsive level and subsequent decay of the molecule. Therefore, this process if of a threshold character and its efficiency depends strongly on a mean electron in a discharge. However, even under optimum conditions the energy cost of atom exceeds markedly a half of 
molecule dissociation energy.

In gas dissociation by an electron beam a certain portion of electron energy is consumed by dissociation of molecules. Since molecular dissociations takes place as a result of secondary processes after passing a fast electron, the energy cost of atom in this case depends not strongly on the electron energy in the beam and is in several times excess of the molecule dissociation energy. Thus, according to Table 1 , the averaged ratio of the energy cost of fluorine atoms formation under the effect of an electron beam to the energy of fluorine molecule dissociation amounts to $3.8 \pm 1.3$.

A photodissociation of molecules is capable of providing the least values of atom energy cost. This is concermed with the fact that in photodissociations of molecules, secondary processes which consume photons are absent in gas. For that reason the photodissociation of molecules is a convenient way to obtain atoms in a gas. But at high intensities of the process the use of radiation to obtain atoms generate a variety of additional problems which reduce potentialities of this method and make it less convenient in comparison with others.

In Table 1 energy costs of fluorine atom formation in a molecular fluorine are compared at different ways of gas excitation. As it is seen, in the discharge this value depends drastically on the discharge parameters; this value for other ways of energy insertion in gas can be predicted before hand with an accuracy not worse than 50\%. Let us note that the energy of fluorine molecule dissociation is equal to $1.63 \mathrm{eV}$, i.e. the minimum energy needed to form one fluorine atom amounts to $0.82 \mathrm{eV}$. In all cases an essentially higher energy is consumed for this.

Since the molecule dissociation as result of irradiation of gas by an electron beam proceeds under the action of secondary electrons, which initial energy is in several fold excess of the molecule ionization potential, one can expect that the order of magnitude for the energy cost of fluorine atom will be kept either at the substitution of fluorine molecule by other fluorine-containing molecules, or at changes in a gas composition. Taking into account this circumstance we included in Table 1 a cost of fluorine atom formation from $\mathrm{SF}_{6}$. The measurements couducted in [13] give the vaIue $6.5 \mathrm{eV}$ for $\mathrm{CF}_{4}$ and $5.6 \mathrm{eV}$ for $\mathrm{C}_{5} \mathrm{~F}_{12}$ for the energy cost of fluorine atom formation at the gas excitation by the electron beam, provided the vaIue $4.5 \mathrm{eV}$ is taken as an energy cost of fluorine from $\mathrm{SF}_{6}$. Naturally, these figures will be varied depending on a mixture composition, but, as it is seen, all obtained figures lie in not a very wide interval. Taking this into account and making statistical averaging of the given results one can recomend the following value for an energy cost of fluorine atom at the dissociation of fluorine-containing molecules by an electron beam:

$$
E_{\mathrm{F}}=6 \pm 2 \mathrm{eV}
$$

This corresponds to the efficiency of molecule dissociation (i.e. the por tion of input energy consumed by dissociation ) $17 \pm 4 \%$.

As is seen from Table 1, the energy cost of fluorine atom formation in the discharge depends significantly on discharge parameters. The mechanism of fluorine dissociation in the discharge was analyzed by D.J.Slovetakif $[14,15]$. Based on the sum total of data he claims that the fluorine dissociation in a discharge can be explained neither by the dissociative 
attachment of electrons to a molecule, nor by the step excitation of vibrational levels of the fluorine molecule ground electron state. In these cases the effective constant of dissociation rate should increase with the growth of pressure, what is contrary to observed dependences. The dissociation in the molecular fluorine discharge is a result of an electron excitation of molecule to a repulsive term. This statement agrees with the physics of process, because the fluorine molecule has several low-lying repulsive terms ( see, for example, $[16]$ ).

\section{Table 2}

The energy cost of dissociation of $\mathrm{CO}_{2}\left(\mathrm{CO}_{2} \rightarrow \mathrm{CO}+\frac{1}{2} \mathrm{O}_{2}-2.90 \mathrm{eV}\right)$ molecule in a glow discharge ${ }^{*}$ at $E / P=24 \mathrm{~V} /(\mathrm{cm}$.Torr) [17]

\begin{tabular}{c|c|c}
\hline $\begin{array}{l}\text { Relation between } \\
\text { amount of } \mathrm{CO}_{2}, \mathrm{~N}_{2} \\
\text { and He in mixture }\end{array}$ & $\mathrm{K}_{\text {diss }}, \mathrm{cm}^{-1}$ Torr & $\begin{array}{c}\text { Fnergy expended in } \\
\text { destruction of one } \\
\mathrm{CO} \text { molecule, } \mathrm{eV}\end{array}$ \\
\hline $100: 0: 0$ & $0.35 \pm 0.5$ & $68 \pm 12$ \\
$4: 4: 92$ & $6.7 \pm 1.5$ & $3.6 \pm 0.8$ \\
$6: 12: 82$ & $5.5 \pm 0.5$ & $4.4 \pm 0.4$ \\
$7: 7: 86$ & $3.4 \pm 1$ & $7.1+2.9$
\end{tabular}

*Energy $\mathcal{E}$ expended in dissociation of one molecule is expressed through a constant of molecule dissociation rate $K_{\text {diss }}$ by an electron impact in discharge, by the relation $\varepsilon=e E w / N k$ diss, where $E$ is the electric field strengh in a discharge, $w$ - is the electron drift velocity, $N-$ is the density of molecules.

The sharp dependence of atom energy cost on discharge parameters is also observed in the cases of other gases. Values of this characteristic at various composition of the mixture for $\mathrm{CO}_{2}$ dissociation are given in Table 2. An addition of $\mathrm{He}$ to $\mathrm{CO}_{2}$ increases the electron mean energy in the discharge, which with a sufficient $\mathrm{CO}_{2}$ concentration leads to the decrease in energy expended in dissociation of an molecule. In paper [18], where a dissociation of $\mathrm{CO}_{2}$ in a glow discharge in the mixture $\mathrm{CO}_{2}: \mathrm{He}(40: 10)$ was a studied, the energy expended in one $\mathrm{CO}_{2}$ molecule dissociation amounted to $113 \mathrm{eV}$ ( under these conditions, 23\% of input power is expended in dissociation).

The effective dissociation proceeds under step the excitation of molecules when the breaking of molecule is accomplished from excited states. This is feasible at a sufficient input discharge power and electron density in the discharge, if collisions of one molecule with electrons happen frequently enough. Values of the energy cost of nitrogen atom formation in nitrogen are given in Table 3 for various vibrational temperature. The data are based on calculations $[19]^{*}$ )

*) Glow discharge investigations carried out in paper [13] for a pure $\mathrm{CO}_{2}$ have shown that the dissociation involves an electron excitation of $\mathrm{CO}_{2}$ molecule into one repulsive terms: $e+\mathrm{CO}_{2} \longrightarrow e+\mathrm{CO}_{2}\left(\mathrm{~A}^{\prime} \mathrm{L}\right)-7 \mathrm{eV} \rightarrow e+\mathrm{CO}_{2}\left(\mathrm{a}^{3} / \mathrm{T}\right)-10,5 e \mathrm{~V} \rightarrow e+\mathrm{CO}+0$. Minimum expenditures in one $\mathrm{CO}_{2}$ molecule dissociation under optimal conditions for a glow discharge, come up to $10 \mathrm{eV}$ per molecule. 
Table 3

The energy cost of nitrogen atom formation at the dissociation of nitrogen molecules in the discharge according to calculations [19] for $\mathrm{E} / \mathrm{N}=6 \cdot 10^{-16} \mathrm{~V} \mathrm{~cm}{ }^{2}$

\begin{tabular}{|c|c|c|c|}
\hline T, K & 300 & 2100 & 4900 \\
\hline Energy cost of atom, eV & 370 & 220 & 100 \\
\hline
\end{tabular}

As is seen, with the increase in vibrational temperature the energy cost of atom formation decreases significantly, since in this case the dissociation of molecules is facilitated. But the energy cost of nitrogen atom formation itself exceeds many times the molecule dissociation energy. Such is the case in CO $[20,21]$. This is primarily explained by a high dissociation energy of $\mathrm{N}_{2}$ and $\mathrm{CO}$ molecules, so that it exceeds considerably the electron mean energy and the dissociation process can prove to be multistage. Besides, electron - excited states of $\mathrm{N}_{2}$ and $\mathrm{CO}$ molecules, which are excited effectively by an electron impact, are stable and do not result in the molecule dissociation [22]. Thereby, the gas discharge is not suited for dissociation of $\mathrm{N}_{2}$ and $\mathrm{CO}$.

However, for gases with a moderate dissociation energy the gas discharge is the effective means of atom generation. This can be illustrated on the example [23] where oxygen dissociation was performed. Such a process was accomplished on UHF-discharge $\left(2.4510^{9} \mathrm{~Hz}\right)$ with input power $1 \mathrm{kw}$. The oxygen (21\%) - helium (79\%) mixture was introduced into this discharge at a pressure of 5.2 Torr. The energy cost of oxygen atom formation was $11 \mathrm{eV}$, i.e. the oxygen dissociation consumed $23 \%$ of the discharge input energy.

In this case, $18 \%$ of the energy was expended in heating the gas, and $50 \%$ of the input energy was radiated. As is seen, over a half of the discharge energy absorbed by gas consumed by the oxygen dissociation.

A thermal dissociation of molecules is of specific interest. The energy cost of $\varepsilon_{A}$ atom formed due to the thermal dissociation:

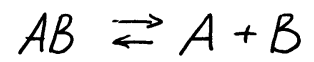

accounts for:

$$
\varepsilon_{A}=D+\frac{[A B]}{[A]} \int_{T_{0}}^{T} C_{A B} d T+\int_{T_{0}}^{T} C_{A} d T+\frac{[B]}{[A]} \int_{T_{0}}^{T} C_{B} d T \text {, }
$$

where $D$ is the molecule dissociation energy, $T_{0}$ is the initial temperature; $\mathrm{C}_{\mathrm{X}}$ is heat capacity for a corresponding gas component; [X] is the density of the given sort particles. Formula (2) takes into account that in order to decompose molecule we heat-up gas up to a certain temperature, so that the energy is expended in heating atoms and molecules as well as in breaking bonds in a molecule. For two-atomic molecules consisting of the same atoms $\left(\mathrm{A}_{2} \rightleftarrows 2 \mathrm{~A}\right.$ ) this formula changes to the shape

$$
\sigma_{A}=\frac{1}{2} D+\frac{\left[A_{2}\right]}{[A]} \int_{T_{0}}^{T} C_{A_{2}} d T+\int_{T_{0}}^{T} C_{A} d T .
$$

From this formula it is followed that the using of present method at a sufficient heating provides the cost of atom formation, being less than molecular dissociation energy. Indeed, a noticeable degree of dissociation is attained at low thermal energies of particles as compared with the energy 
of dissociation of molecules (T«D). Since $C_{A_{2}} \sim C_{A} \sim 1$, from this is follows that within this temperature range the second and third addenda in formula, (3) or three last addenda in formula (2) make a small contribution

to the energy cost of atom. Values of the fluorine atom energy cost are given in Table 4, calculated from formula (3) with allowance for equilibrium concentrations of an atomic and molecular fluorine. As it is seen, at not very low temperatures the energy cost of fluorine atom is comparable with the energy of molecule dissociation.

Table 4

The energy cost of fluorine atom formation, eV, at the interaction with a hot surface $\left(\mathrm{F}_{2} \rightleftarrows 2 \mathrm{~F}=1.63 \mathrm{eV}\right)$

\begin{tabular}{|c|c|c|c|l|l|}
\hline \multirow{2}{*}{$\begin{array}{c}\text { Fluorine } \\
\text { pressure } \\
\text { Torr }\end{array}$} & \multicolumn{5}{|c|}{$\mathrm{T}, \mathrm{K}$} \\
\cline { 2 - 6 } & 800 & 900 & 1000 & 1100 & 1200 \\
\hline 10 & $2.9(175)$ & $1.55(26.6)$ & $1.21(6.76)$ & $1.05(2.72)$ & $1.04(1.69)$ \\
100 & $7.1(24.4)$ & $2.82(6.02)$ & $1.70(2,25)$ & $1.22(1.39)$ & $1.18(1.25)$ \\
\hline
\end{tabular}

Along with the thermal dissociation of molecules, secondary processes take place, lowering the energy cost of atom. In particular, when a dissociation of molecules occurs on a heated surface, the energy is expended not only in heating a gas and dissociation of molecules but in radiation of the surface. Values of the energy cost of fluorine atom at the $F_{2}$ thermal dissociation near a nickel heated surface are given in Table 4 in parentheses. In this case, the surface is believed to radiate as an black body of a given temperature and an atom formed near the surface is used, not returning to it any more. For probability of dissociation a fluorine molecule colliding with the heated nickel surface, use was made of formula $[10] \mathrm{P}=1.9$. $-10^{5} \exp (-17800 / \mathrm{T})$. Let us note that under realistic conditions the atom energy cost is higher than that of the mentioned one, since together with dissociation of molecules there takes place recombination of atoms on the surface. In doing so, the energy cost of atom formation depends on particular conditious in a chemical reactor.

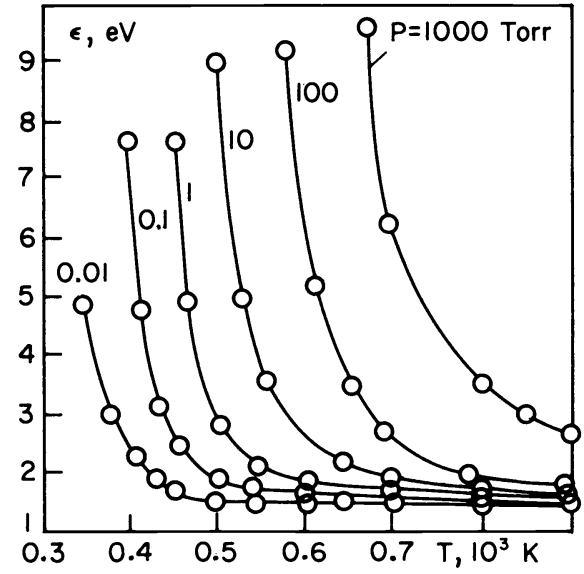

Fig. 1. Dissociation energy as a function of the temperature
Fig. 1 shows another example of the considered type, concermed with dissociation of ozone near a heated surface:

$$
\mathrm{O}_{3} \rightleftarrows \mathrm{O}_{2}+\mathrm{O}-1.05 \mathrm{ev}
$$

The surface temperature is lower, so that the heated surface radiation is less significaut. Ozone and atomic oxygen on the heated surface are in a thermodynamic equilibrium.

By analyzing the thermal method of atom formation as a result of dissociation of molecules near a heated surface, it should be noted that it

is convenient at not very high temperatures of the surface. High temperatures lead to a strong surface radiation, as well as to its degradation 
as a result of material evaporation and chemical processes on the surface. Therefore, the thermal way of molecule dissociation near a heated surface is suitable only for molecules with a moderate energy of dissociation.

Nevertheless, the manner of atom generation itself as a result of a high heating a gas is reather effective. The gas heating is convenient to perform if an electron current is passed through a gas - in a gas discharge, in an are discharge, etc. In contrast to a case of a heated wall, in this case the heated region radiation can play no part, since a heated gas ( or a plasma) in a main frequency region in optically transparent. Atoms generated in a gas hot region diffuse to a cold one where can be used.Tables 5-7 give atom concentrations and energy costs of atom formation, corresponding to heating the simpliest diatomic gases under conditions of a thermodynamic equilibrium in it. The cost of atom formation was determined from formula (3). Here, $C_{A}=5 / 2$ and it was assumed that at temperatures under consideration a molecule is highly vibrationally excited and its heat capacity $C_{A}=9 / 2$, so that formula (3) takes the form:

$$
\varepsilon_{A}=\frac{D}{2}+\frac{g}{2} T \frac{\left[A_{2}\right]}{[A]}+\frac{5}{2} T .
$$

Thus, based on Tables 5-7 we can conclude that by heating a gas with the aid of an equilibrium plasma and by keeping in it (gas) a thermal equilibrium, it can be dissociated with a high efficiency. A specific problem lies in atom transport to a place where they are used; and this process will be require an additional energy expenditures. As for generation of atoms, then within the considered pressure range of $0.1-10$ Torr for $\mathrm{H}_{2}, \mathrm{~N}_{2}$ and $\mathrm{O}_{2}$ a practically complete dissociation comes at $\mathrm{T} / \mathrm{D}=0.06-0.07$ ( $\mathrm{T}-\mathrm{a}$ temperature, $D$ - an energy of molecule dissociation; in this case, a portion of input energy expended in heating a gas for dissociation of molecules, exceeds 70\%).

Table 5

The energy cost of formation, $e V$, and concentrations of hydrogen atoms, \% ( in parentheses) for heated hydrogen under conditions of thermodynamic equilibrium $\mathrm{H}_{2} \rightleftarrows 2 \mathrm{H}-4.48 \mathrm{eV}$

\begin{tabular}{|c|c|l|l|l|l|l|l|l|}
\hline P. & \multicolumn{10}{c|}{ T, K } \\
\cline { 2 - 8 } 0.1 & 2600 & 2800 & 3000 & 3200 & 3400 & 3600 & 3800 & 4000 \\
\hline \multirow{4}{*}{0.3} & $3.3 \cdot 10^{3}$ & 170 & 14 & 3.3 & 3.1 & 3.1 & 3.1 & 3.2 \\
& $(0.03)$ & $(0.64)$ & $(8.8)$ & $(60)$ & $(98)$ & $(100)$ & $(100)$ & $(100)$ \\
& $5.6 \cdot 10^{3}$ & 290 & 23 & 4.0 & 3.1 & 3.1 & 3.1 & 3.2 \\
& $(0.02)$ & $(0.37)$ & $(5.2)$ & $(42)$ & $(95)$ & $(100)$ & $(100)$ & $(100)$ \\
& $1.0 \cdot 10^{4}$ & 530 & 41 & 5.6 & 3.1 & 3.1 & 3.1 & 3.2 \\
& $(0.01)$ & $(0.20)$ & $(2.9)$ & $(26)$ & $(87)$ & $(100)$ & $(100)$ & $(100)$ \\
3 & $1.7 \cdot 10^{4}$ & 920 & 7.1 & 8.8 & 3.2 & 3.1 & 3.1 & 3.2 \\
& $(0.006)$ & $(0.12)$ & $(1.7)$ & $(16)$ & $(72)$ & $(99)$ & $(100)$ & $(100)$ \\
10 & $3.2 \cdot 10^{4}$ & $1.710^{3}$ & 130 & 1.5 & 3.6 & 3.1 & 3.1 & 3.2 \\
& $(0.003)$ & $(0.06)$ & $(0.91)$ & $(9.0)$ & $(52)$ & $(96)$ & $(100)$ & $(100)$ \\
& & & & & & & & \\
\hline
\end{tabular}

In the case of three-atomic molecules, whose different degrees of freedom are excited equally, the dissociation efficiency is lower. This is conditioned by the necessity to excite more degrees of freedom, which consumes higher energy. Hence the ratio of temperature at which a noticeable dissociation proceeds, to dissociation energy in the case of three-atomic 
molecules, when they decompose to diatomic ones, is markedly higher than in the event of dissociation of diatomic molecules. For instance, for the process of dissociation of molecule $\mathrm{CO}_{2}$ :

$$
\mathrm{CO}_{2} \rightleftarrows \mathrm{CO}+\frac{1}{2} \mathrm{O}_{2}-2,9 e \mathrm{~V}
$$

the maximum dissociation efficiency while heating under equlibrium conditions is $40 \%$ [24].

Table 6

The energy cost of formation, eV, and concentration of atom, $\%$ ( in parentheses) for heated nitrogen under conditions of thermodynamic equilibrium $\mathrm{N}_{2} \longrightarrow 2 \mathrm{~N}-9.77 \mathrm{eV}$

\begin{tabular}{|c|l|l|l|l|l|l|l|l|l|}
\hline \multirow{2}{*}{$\begin{array}{c}\text { P, } \\
\text { Torr }\end{array}$} & \multicolumn{10}{|c|}{ T, K } \\
\cline { 2 - 9 } 0.1 & 5200 & 5400 & 5600 & 5800 & 6000 & 6200 & 6400 & 6600 & 6800 \\
& 620 & 120 & 27 & 9.6 & 6.4 & 6.2 & 6.3 & 6.3 & 6.4 \\
0.3 & $(0.32)$ & $(1.8)$ & $(8.5)$ & $(32)$ & $(67)$ & $(97)$ & $(100)$ & $(100)$ & $(100)$ \\
& 1100 & 210 & 45 & 13 & 6.9 & 6.3 & 6.3 & 6.3 & 6.4 \\
& $(0.19)$ & $(1.0)$ & $(5.0)$ & $(20)$ & $(58)$ & $(92)$ & $(99)$ & $(100)$ & $(100)$ \\
1.0 & 1900 & 370 & 80 & 21 & 8.5 & 6.4 & 6.3 & 6.3 & 6.4 \\
& $(0.10)$ & $(0.57)$ & $(2.8)$ & $(11)$ & $(38)$ & $(80)$ & $(97)$ & $(100)$ & $(100)$ \\
3.0 & 3400 & 640 & 140 & 35 & 10.6 & 6.7 & 6.3 & 6.3 & 6.4 \\
& $(0.06)$ & $(0.33)$ & $(1.6)$ & $(6.8)$ & $(25)$ & $(63)$ & $(93)$ & $(99)$ & $(100)$ \\
10 & 6100 & 1200 & 250 & 60 & 18 & 8.1 & 6.4 & 6.3 & 6.4 \\
& $(0.03)$ & $(0.18)$ & $(0.88)$ & $(3.8)$ & $(14)$ & $(43)$ & $(82)$ & $(97)$ & $(100)$ \\
& & & & & & & & & \\
\hline
\end{tabular}

In this case it is clear that in heating a gas under non-equilibrium conditions one can attain a higher efficiency of dissociation, for then the input energy is expended in not all degrees of freedom. Since the molecule dissociation is accomplished through a vibrational excitation of molecule, the effective dissociation can take place under non-equilibrium conditions, in which the population of vibrationally excited states is higher than under equilibrium conditions. Therefore, the molecule dissociation was suggested to be performed in a non-equilibrium plasma with a high vibrational temperature $[13,25-28]$.

Let us consider the manner of heating a carbon dioxide under non-equilibrium conditions, when an rotational and translational temperatures fixed at low level and only the vibrational temperature increases, which is the some for various vibrational degrees of freedom. Under optimum conditions (pressure - $1 \mathrm{~atm}$, finite temperature - $3200 \mathrm{~K}$ ) we obtain a maximum efficiency of dissociation, being equal, according to calculations [29], to $61 \%$. This seems to be a maximum figure for the dissociation efficiency. However, experiments $[28,31]$ show that the efficiency of dissociation over $80 \%$, is observed in the UHF - discharge. Let us analyze these data.

In a non-equilibrium gas the dissociation efficiency is growing for two reasons. Firstly, a relatively less energy is used in an excitation of translational and rotational degrees of freedom. Secondly, because of anharmonicity of molecules, the relative number of vibrationally - excited molecules increases. Therefore, the same degree of dissociation is attained 
at a lower vibtational temperature than at the absence of anharmonicity. However, since in an equilibrium gas of diatomic molecules the efficiency

Table 7

The energy cost of formation, $\mathrm{eV}$, and concentration of oxygen atoms, \% ( in parentheses) for heated oxygen under conditions of thermodynamic equilibrium $\mathrm{O}_{2} \rightleftarrows 20-5.12 \mathrm{eV}$

\begin{tabular}{|c|l|l|l|l|l|l|l|}
\hline \multirow{2}{*}{$\begin{array}{c}\text { P, } \\
\text { Torr }\end{array}$} & \multicolumn{7}{|c|}{ T, K } \\
\cline { 2 - 7 } & 2600 & 2800 & 3000 & 3200 & 3400 & 3600 & 3800 \\
\hline 0.1 & 7500 & 250 & 14 & 3.4 & 3.3 & 3.3 & 3.4 \\
& $(0.013)$ & $(0.43)$ & $(8.6)$ & $(70)$ & $(99)$ & $(100)$ & $(100)$ \\
0.3 & $1.3 \cdot 10^{4}$ & 430 & 24 & 3.8 & 3.3 & 3.3 & 3.4 \\
& $(0.007)$ & $(0.25)$ & $(5.0)$ & $(52)$ & $(98)$ & $(100)$ & $(100)$ \\
1 & $2.4 \cdot 10^{4}$ & 800 & 42 & 4.9 & 3.3 & 3.3 & 3.4 \\
& $(0.004)$ & $(0.14)$ & $(2.8)$ & $(33)$ & $(95)$ & $(100)$ & $(100)$ \\
3 & $4.1 .10^{4}$ & 1400 & 72 & 7.0 & 3.3 & 3.3 & 3.4 \\
& $(0.002)$ & $(0.08)$ & $(1.6)$ & $(21)$ & $(88)$ & $(100)$ & $(100)$ \\
10 & $7.5 \cdot 10^{4}$ & 2500 & 130 & 11 & 3.4 & 3.3 & 3.4 \\
& $(0.001)$ & $(0.04)$ & $(0.89)$ & $(12)$ & $(72)$ & $(99)$ & $(100)$ \\
\hline
\end{tabular}

of their dissociation proves to be high, the study of this value variation in the non-equilibrium diatomic gas loses its practical interest.

The non-equilibrium has a significant effect on efficiency of dissociation of three-atomic molecules. We shall further consider the most completely studied case of dissociation of carbon dioxide molecules:

$$
\mathrm{CO}_{2} \rightleftarrows \mathrm{CO}^{\prime}+\frac{1}{2} \mathrm{O}_{2}-2,9 e \mathrm{~V}
$$

The maximum efficiency of this process amounts to $40 \%$ [24] in the case of thermodynamic equilibrium. In a non-equilibrium gas, when vibrational temperature exceeds considerably the translational and rotational ones, under optimal conditions ( $\mathrm{P}=1$ bar $\mathrm{T}=3200 \mathrm{~K}$ ), the maximum dissociation efficiency comes up to $61 \%$ [29]. It was assumed in calculation [29] that an equilibrium is take place between various vubrational degrees of freedom for excited states. Measurements [28] within the pressure range of 100 Torr at a gas excitation by an UHF-discharge result in an optimum dissociation efficiency exceeding $80 \%$. The authors explain such a high efficiency as a result of an excitation of one vibrational mode. But this assumption seems to us to be incorrect for two reasons. First, an excitation up to the states leading to dissociations, takes place as a result of many consecutive transitions between molecule vibrational states. Separate vibrational states are unlikely to be separated so that in this case an exchange between different vibrational degrees of freedom will happen. Second, the mentioned assumption requires for that initially all input energy be contributed to one dergee of freedom. Direct experiments [32] show that under optimum conditions ( electron mean energy - 1-1.5 eV), about $65 \%$ is contributed to an antisymmetric vibrational mode. Therefore, the efficiency of carbon dioxide dissociation calls for an additional analysis. 


\section{References}

1. Iegasov V.A., Smimov B.M., Chayvanov B. B., in "Chimiya plasmy", Atomizdat, M., 1982, v.9, p.100.

2. Parker J., Stephens R.R., J.Quant. Electron., 1973, v.9, p.643.

3. Fehsenfeld F.C., Evenson K.M., Broida H.C., Rev•Scient. Instrum., 1965, v.36, p.294.

4. Zaitsev V.V., Zverevskaya E.J., Klimov V.D., Khim. Vys. Energ., 1978, v.12, p.516; Zh. Techn. Phys., 1978, v.48, p.1541, Zh.Phys. Khim., 1980, $\mathrm{v} .54, \mathrm{p} .667$.

5. Lebedev O.G., Murashov M.V., Prusakov V.N॰, Khim. Vys. Energ., 1977, $\mathrm{v} .6, \mathrm{p} .533$.

6. Gross R.W., Wesner F.- Appl.Phys.Lett. 23, 5591 (1973).

7. Whittier J.S. et.al.J.Appl. Phys. 47, 3542 (1976).

8. Wilson J., Chen H.I., Fyfe W., J.Appl.Phys. 44, 5447 (1973).

9. Goetschel C.T. et.al. J.Amer.Chem.Soc. 21, 4702 (1969).

10. Artjukhov A.A. et.al. Khim.Vys. Energ. 1976, v.10, p.513.

11. Bezmelnizyn V.N. et.al. Preprint I.V.Kurchatov Atomic Energy Institute N 2804, 1977.

12. Bezmelnizyn V.H., Sinjanskii B.F., Chayvanov B.B. in "Chimiya plasmy", Atnmizdat, 1979, v.6, p.89.

13. Bushkin A.S. et.al. Kvantovaja Electron., 1983, v.10, p.428.

14. Slovetskii D.I. "Mekhanizmy Khimickeskich reaczii $v$ neravnovesnoi Plasme", Ii., Nauka, 1980.

15. Slovetskii D.I., in "Khimiya plasmy", M., Atomizdat, 1983, v.10, p.108.

16. Shlyapnikov G.V., Shmatov I.P., Opt. i Spectrosc., 1978, v.45, N 3 , p.487.

17. Austin J.M., Smith A.I.S., Browne P.G. Phys.Iett. 46A, 427. (1974).

18. Balik E.A. et.al. J.Appl.Phys. 1975, v.46, p.1322.

19. Alexandrov N.I., Kochakov A.M., Son E.J., Physica plasmy, 1978, v.4, p.169, 1182 .

20. Al exandrov N.I., Konchakov A.M., Son E.J., Zh. Techn. phys., 1979,v.49, p.1194, 1200 .

21. Alexandrov N.I., Son E.J., in "Khimiya plasmy", M, Atomizdat, 1980,v.7, p.35.

22. Slovetskii D.I., ibid, 1974, v.1, p.156.

23. Capitelli M., Dilonardo M. Chem.Phys. 20, 417 (1970).

24. Mamikonjan E.R., Polak T.•., Slovetskii D.I. Khim•Vys•Energ•, 1972,v.6, p. 483.

25.Jeffers W.Q., Wiswall C.E. J.Quant.Electr., 10, 861 (1974).

26. Slovetskii D.I., in "Khimiya plasmy", M., Energoatomizdat,1984,v.11, $\mathrm{p} .184$.

27. Polak I.S. "Neravnov. khimic. kinet. i jeje primen",M,Nauka, 1979.

28. Rusanov V.D., Fridman A.A., Sholin G.V.Usp.Phys.Nauk, 1981, v. 134,p.135.

29. Evseyev A.V., Eletskii A.V.,Palkina I.A., Voprosy atomnoi nauki $i$ technik Ser. At-vodor. energetica, 1979, v.1(S), p.30-42.

30.7hivotov B.K., R usanov V.D., Fridman A.A., in"Khim.plasmy"M.,Atomizdat, 1982, v. 10, p.206.

31. Rusanov V.D., Fridman A.A.,Fizika Khim. activ.plasmy,M, Nauka, 1984.

32.Bulos B.P., Phelps A.V. Phys.Rev. A, 14, 615 (1976). 